\title{
Nurses' happiness and awareness of their influence on work in governmental and private hospitals
}

\author{
Ibrahim Yahya Alhakami*1, Omar Ghazi Baker² \\ ${ }^{1}$ Nursing Administration Department, Jeddah Psychiatric Hospital, Kingdom of Saudi Arabia \\ ${ }^{2}$ College of Nursing, King Saud University, Riyadh, Kingdom of Saudi Arabia
}

Received: June 13, 2018

DOI: $10.5430 /$ cns.v7n1p21
Accepted: August 15, 2018

Online Published: August 28, 2018

URL: https://doi.org/10.5430/cns.v7n1p21

\begin{abstract}
Nurses passed through many stressful experiences during nursing work. Emotional support and considering their emotional needs can alleviate such work-associated tension and contribute to the quality of their performance. Nurses' happiness and awareness of their influence on work are necessary blocks to build the nurses' emotional steadiness, and thus their work retention and turnover rates would be maintained. This study establishes to attain two aims: First: to identify the levels of nurses' happiness and the awareness of their influence on work, in governmental and private hospitals, in Jeddah, Kingdom Saudi Arabia (KSA). Second: to determine the correlation between those perceived variables. Thus, a descriptive, correlative and comparative research design was employed with 300 registered nurses in King Abd El Aziz governmental hospital and 200 registered nurses in private International Medical Center, Jeddah, KSA. A survey method was applied for data collection, and the study questionnaire involved three parts. Part one is about nurses' personal profile. The second part included happiness subscale, which was developed by Warr et al., in 1979 and the third one is the individual influence on the work scale that was developed by Toode et al., in 2015. The study findings reveal that the majority of both study groups reported a fair level of happiness, with a moderate awareness level of their influence on work. Additionally, nurses who are working in private hospital have a higher awareness level of their influence on work and happiness, more than the nurses who are working in the governmental hospital. Study subjects who experience a high level of happiness have a high level of awareness of their influence on the work. Therefore, the correlation coefficient among both research variables in both hospitals indicated a noteworthy stronger positive correlation. Conclusion and recommendations: nurse's happiness and awareness of their influence on work are essential emotional aspects to be considered in nursing management. Fitting plan for nurses' psychological stability at work should be designed and implemented, particularly in governmental hospitals in Jeddah. Also, Nurse Manager should assess and maintain a high nurses' happiness level and awareness of their influence on the work; consequently, nurses work product will be improved. Further studies are needed to investigate the study variables by different measurement tools for behaviors or skills. A study about an assessment of the relation between the nurse's emotional status and their performance is suggested.
\end{abstract}

Key Words: Nurse's happiness, Influence on work, Governmental and private, Hospitals

\section{INTRODUCTION}

Individual emotional status involves any attentiveness experience, described by imperative intellectual activity and a definite extent of happiness or unhappiness (pleasure or displeasure). Emotion is often linked to mood, disposition, personality, and motivation. Cognition and emotion are almost linked. Cognition includes our thoughts and interpreta-

\footnotetext{
*Correspondence: Ibrahim Yahya Alhakami; Email: aa.1hh@ hotmail.com; Address: Nursing Administration Department, Jeddah Psychiatric Hospital, Kingdom of Saudi Arabia.
}

Published by Sciedu Press 
tions of events, ideas about ourselves and people, and consequently, emotion shapes our attitudes and feelings that facilitate the understanding of life situations and others. So, feelings or emotions, and cognition are interrelated. Therefore, emotional needs at work, directed all behaviors of the employee, to be productive or destructive. Some nurses' work, is just a mean to the financial resource; but for others, work is the core aspect of their life. The second type of nurses is internally motivated through two important empowerments: First, an enhanced emotional condition that translates through an elevated level of happiness; Second, prominent perceiving of their influence on work. Both empowerments are essential features of work motivation and have a great positive influence on nurses' work performance, retention, and satisfaction. Emotional strength, happiness and nurse's acknowledgment of their influence on work are considered internal motivators that affect constructively work quality and institutional achievement. Worldwide, there are multiple efforts have been done to reserve nurses in their jobs, yet, there is an observed shortage in the nursing workforce. ${ }^{[1-3]}$ Consequently, it is a mandate for Nurse Managers to do their best to assess nurses needs physically and psychologically. As well, nurse manager should tailor a positive work climate and help nurses to be happy and familiar with the value of their accomplishment. Healthcare work quality is dependent on the professional competency, knowledge level, and as well, the psychological constancy of the nurse professionals.

Happiness in work is the inner motive which can drive an employee to have better attitudes, knowledge, thoughts, and behaviors about the nature of the field and the organization. Happiness is the cornerstone of individual well-being that relies on the employees' awareness of the sources of pleasure in the healthcare agency. Occasionally, happiness may be called well-being, and alternatively, both terms are used almost by the same meaning. In occupational health psychology, employee happiness is dependent on many organizational factors such as supervision, staff development, work involvement, etc., and personal factors such as values, beliefs, feelings, thoughts, etc. Therefore, happiness is viewed as the main mental, emotional and intellectual personal needs of a human being, as well it is an essential instrument to alleviate work stressors. ${ }^{[1,4,5]}$ Many references consider the organizational factors but neglect the personal ones.

Happiness can be defined as "an emotional or affective state that is characterized by feelings of enjoyment and satisfaction, which is often equated with morale, contentment, wellbeing, life satisfaction, successful and cheerful quality of life." Additionally, happiness is referring to a subjective welfare which involves constructive emotion of life agreement in a particular period. ${ }^{[6-8]}$ If the nurses are happy doing work activities, they will have a high level of internal motivation which depends on their values, preferences, and priorities. Furthermore, happiness is a marker of comfort which is exemplified by emotions ranging from satisfaction to intense joy. Happiness in work directs the employee cognitive process to inner motivation and numerous positive job decisions about the position, employee comparisons, work environment, work decision involvement and work satisfaction. ${ }^{[2,9,10]}$

Employees' happiness is strongly associated with their perception to ones' performance and to which extent, they recognize their influence on work production. Influence on work means the capability or control of the employee to be a persuasive force or create effects on the accomplishments, confidences, work behaviors and organizational outcome as a whole. Moreover, nurses' identification of their influence on work is a command that directs the employee internal control on work performance level. Influencing work product and recognizing it, will enhance the employee to work cooperatively and effectively. Furthermore, nurses with a considerable level of awareness of their influence on work will have higher autonomy with work and life, colleague's engagement, work motivation, and organizational commitment. Nurse Manager supervision can help employees to have a great consciousness of their influence on their work. Moreover, when the Nurse Manager orient, adivice and instruct subordinates about their work activities' value, they will gain their trust with job confidence and, establish a constructive relationship in the work climate. In the same time, when the Nurse Managers determine the nurses' influence on work, they may allow the nurses to attain higher positions, incentives, days off, and other gratifications. However, nationally and internationally and in many healthcare systems, there is a limited understanding of employees' influence on work in the most of nursing literature. ${ }^{[1-3]}$

In accordance with litrature and the most of work motivation theoires, identification of ones' influence on work among nursing workforce has an apparent constructive effect on their work motivation. Self-determination theory discussed the four styles of motivation that are linked to the employee work motivation: Extrinsic Motivation, Intrinsic Motivation, Introjected Motivation, and Identified Motivation. Consistent with self-determination theory, the employees who are internally motivated will work to their satisfaction and have a high awareness of their influence on work, with consideration to introjected, intrinsic, and self-determined regulations. Perception of the ones' impact on work is an internal force of the three motivational regulations because the employee tends to link between the ego and believe of work values which ex- 
tend to the appreciative influence on work with empowering and motivation in performance. When the employee felt a high degree of introjected motivational rules features, his/her values will be tailored to realize his/her achievement at work. Accordingly, pride, high self-esteem, and self-importance will become visible. Additionally, when the employees experience the acknowledgment of their influence on work, they will be internally interested in producing the best work outcomes. Thus, the perception of one's influence on work is a crucial force for the intrinsic type of motivational regulation and produced employee gratification. Moreover, it is one aspect of the identified regulation of motivation which representing the employee's awareness of their achievement and included competencies, abilities, knowledge, and values. Accordingly, the employee becomes fully conscious of the work worth, own abilities, and be internally self-appreciated. Nurses with the high perception level of their influence on work, are continuously achievers and almost accomplish their targets on work and life earlier. ${ }^{[3,7,11]}$

Multiple factors may be associated with nurses' awareness of their influence on work. Happiness at work seems to be the most apparent factor that is positively combined with it. Fitting to this view, in the Jazan region, KSA, Almalki et al., in 2012 reported that it is essential to the nurse manager to tailor the work climate with positive influences such as trustworthiness, work achievement consciousness and happiness. As well, there is much-related literature which stresses that workforce retention, motivation, and satisfaction, are supported by nurses happiness in work and their awareness of their work achievement. Happiness and identification of influence on work among nurses have numerous benefits for nurses themselves and organization at all. ${ }^{[1,3,4,12]}$ Thus, promotion of happiness at work and awareness of ones' influence on work among nurses are essential missions of Nurse Managers and prime motivators for their subordinates.

Moreover, it is remarkable that nurses in the private sector are happier and recognizing their influence on work than those who are working in the governmental sector. Nurses' highest reported rates of frustration detect low recognition of work, low motivation and work absenteeism among them in the governmental sector. While in the private sector, it was observed that the administration is focusing on enhancing employees' awareness about performance and frequently improving employees' work motivations' factors. ${ }^{[3,13,14]}$ Therefore, in the private sector, the nurses may find happiness resources and more considerations for their psychological needs. Commonly, in many Arab countries, it has been noticed that the puplic health sector is deficient in the quality of patient care and workforce frustration and dissatisfaction. Inadequate salaries and inappropriate supervision and communication

Published by Sciedu Press are the de-motivating factors among nurses in those countries. Therefore and consequently, a variety of complaints in the recent years add to nurses, particularly in the governmental region. But both sectors are suffering from the nursing workforce shortage. Hence, private or governmental healthcare settings should assess the factors that lead to nurses' work satisfaction such as their happiness and awareness by their influence on work. Nurse Managers have to prepare a motivation plan for nurses' workforce retention. Such approaches should consider the factors that enhance nurse's work psychological inspiration, happiness and nurses' recognition of their influence on work. ${ }^{[3,4,13,15]}$

\subsection{Aim and significance}

Hospitals in Saudi Arabia have suffered from nurses scarcity and their work leave or absenteeism. Considering nurses' perception of their influence on work and their happiness is an important role of the nurse manager. ${ }^{[3,4,12]}$ Therefore, to uphold, stimulate and sustain nursing staff; stakeholders and nurses managers should assess nurses' psychological needs. Awareness of ones' influence on work and own happiness are major perceptions for ensuring and development of effective nursing services in the healthcare sectors. Hence, the present study was conducted for first; identifying nurses' happiness and awareness of their influence on work, in governmental and private hospitals, in Jeddah, KSA. Second; determining the correlation between those variables. This data would be beneficial and exceptional for comprehending the essential aspects of nurses' motivation and configuring their psychological stability as a whole.

\subsection{Research Questions}

- What are the levels of nurses' happiness and awareness of their influence on work in governmental and private hospitals in Jeddah?

- What is the correlation between nurses' happiness and awareness of their influence on work in governmental and private hospitals, in Jeddah?

\subsection{Research hypothesis}

There is a significant parallel correlation between nurses' happiness and awareness of their influence on work in governmental and private hospitals, in Jeddah.

\section{MATerials AND METHOD}

A descriptive correlation cross-sectional comparative research design was conducted to answer the research questions. The data was collected from a total of number 500 out of 1,587 registered staff nurses (300 from King Abd El Aziz 
hospital as a governmental hospital and 200 from the International Medical center as a private one) in Jeddah, KSA. The sample size is estimated by open epidemiological statistical information program (Bernard Rosner, 1999) ${ }^{[16]}$ with a 0.05 margin of error and a $95 \%$ confidence interval. Registered nurses in their hospital departments were selected randomly by proportionate stratified random sampling, and after that, they were recruited in the study sample by systemic random sampling technique. Inclusion criteria for sample selection were: Nurses from both gender, registered in the hospital, no less than six months experience, attended the initial hospital training, on duty at the time of data collection, and willingness to participate in the study by signing the written informed consent.

The instrument of data collection was a structured questionnaire that included three parts: (1) Questions about the nurse's profile. (2) Happiness subscale which was developed by Warr et al., in $1979,{ }^{[1,17]}$ as a tool of measuring the internal psychological status of the employee regarding the concerning work tasks and circumstances that enhances employee happiness. It included selection between three levels of the whole description of emotions and feeling status of the employee. Not too happy $=1$, fairly happy $=2$ and very happy $=3$. (3) The individual influence on work scale which was developed by Toode et al., in $2015,{ }^{[2]}$ to assess the influence on work as perceived by nurses regarding influence in what tasks to do, influence in the intensity (pace) at which to work and influence on how to do the work. It included three items which measured through 5 points Likert scale (1 = None, $2=$ A little, $3=$ Moderate, $4=$ Considerable and $5=$ Total influence). The total score was ranged from 3 to 15 , regarding $3 \leq 6$ pointed to the low level of influence on work; $7 \leq 10$ signifies the moderate level of influence on work and $11 \leq 15$ denotes high influence on a work level.

A pilot study was conducted on 55 nurses from the mentioned settings who were separated from the study sample, and no modifications needed. The current two scales were re-measured for content validity by four academic professional's panel in nursing management, nursing education and psychiatric and mental health nursing to approve content validity. Reliability was re-checked by Cronbach's alpha coefficient statistical test that revealed $>0.7$ for both scales. Written informed consents were signed by the study participants after full explanation of the study purpose and methodology. As well, approvals from the mentioned settings were attained. Subjects were instructed that they have the full voluntary choice to contribute to the study and they were never confronting any penalties in their work when participating in it. Also, they were free to withdraw from the study at any point in time. Anonymity was established for data confidentiality.

\section{Statistical analysis}

Data was fed, coded, edited and analyzed using the PC with Statistical Packages for Social Science (SPSS 20) and Windows Version 10.0. Descriptive statistics were done using numbers, percentage, arithmetic mean and standard deviation. Then Univariate analyses were performed by use of the Chi-square test and variance analysis in $95 \%$ confidence levels. Besides Spearman's rho statistical test which was used to quantify the strength of the association between the study variables. Statistical significance was considered at $p$-value $<.05$ and confidence interval of $(95 \% \mathrm{CI})$.

\section{Results}

\subsection{Nurses' sociodemographic profile and background}

Table 1 represents nurses' sociodemographic profile and background as presented by percentage and according to the type of hospital. The majority of nurses in both the governmental and private hospitals were females respectively (93\% and $89.5 \%$ ), with the considerably larger proportion of older nurses who aged $\geq 40$ years in the private hospital than the governmental hospital (30.8\% vs., $19.8 \%), p<.05$. The nurses who work in the private hospital and live with another subject are significantly more than who work in governmental one (64.5\% vs. $54 \%$ ). The majority of both study groups $(75 \%$ and $75 \%$ ) have bachelor degree qualifications. Although the percentage of nurses who have a Masters' degree was higher in nurses who are working in the private sector $(4.5 \%)$ than those in the governmental hospital $(1.3 \%)$, the differences in the qualifications between the two groups were not statistically significant $p>.05$. For work experience years, the majority of both groups $(89.3 \%$ and $80.5 \%)$ have five to ten years of services in the hospital.

\subsection{Rating nurses' happiness in governmental and pri- vate hospitals}

Figure 1 illustrates the rating of nurses' happiness among both study groups. The majority of both groups $(79.3 \%$ and $68.9 \%$ ) are fairly happy. While, the higher proportion of the nurses, who are working in private hospital and very happy $(24.2 \%)$ which more than those who are working in the governmental one (10.8\%). However, there is a high percentage of the nurses who are working in the governmental hospital and reported that they are not too happy more than those in the private hospital $(10 \%$ vs. $6.8 \%)$ and $p<.05$. 
Table 1. Nurses' sociodemographic profile and background as presented by percentages and according to the type of hospital $($ Gov. $=300$ and Private $=200)$

\begin{tabular}{|c|c|c|c|c|c|c|}
\hline \multirow{3}{*}{ Profile } & \multicolumn{4}{|c|}{ Type of hospital } & \multirow{3}{*}{$\chi^{2}$} & \multirow{3}{*}{$p^{*}$} \\
\hline & \multicolumn{2}{|c|}{ Gov. $(N=300)$} & \multicolumn{2}{|c|}{ Private $(\mathrm{N}=200)$} & & \\
\hline & No & $\%$ & No & $\%$ & & \\
\hline Gender: & & & & & 1.910 & .167 \\
\hline Male & 21 & $7.0 \%$ & 21 & $10.5 \%$ & & \\
\hline Female & 279 & $93.0 \%$ & 179 & $89.5 \%$ & & \\
\hline Age category $(n=468)$ : & & & & & 14.613 & $<.001^{* *}$ \\
\hline$<30$ years & 130 & $45.9 \%$ & 54 & $29.2 \%$ & & \\
\hline $30<40$ years & 97 & $34.3 \%$ & 74 & $40.0 \%$ & & \\
\hline$\geq 40$ years & 56 & $19.8 \%$ & 57 & $30.8 \%$ & & \\
\hline Social status: & & & & & 5.438 & $.020^{* *}$ \\
\hline Living alone & 138 & $46.0 \%$ & 71 & $35.5 \%$ & & \\
\hline Living with others & 162 & $54.0 \%$ & 129 & $64.5 \%$ & & \\
\hline Qualifications: & & & & & 6.405 & .171 \\
\hline Vocational diploma from medical school & 40 & $13.3 \%$ & 19 & $9.5 \%$ & & \\
\hline Specialized education from healthcare college & 8 & $2.7 \%$ & 7 & $3.5 \%$ & & \\
\hline Bachelor degree & 225 & $75.0 \%$ & 150 & $75.0 \%$ & & \\
\hline Master degree & 4 & $1.3 \%$ & 9 & $4.5 \%$ & & \\
\hline Diploma & 23 & $7.7 \%$ & 15 & $7.5 \%$ & & \\
\hline Experience period: & & & & & 8.182 & $.042^{* *}$ \\
\hline$\leq 5$ years & 13 & 4.3 & 16 & 8 & & \\
\hline $5 \leq 10$ years & 286 & 89.3 & 161 & 80.5 & & \\
\hline $10 \leq 15$ years & 15 & 5 & 20 & 10 & & \\
\hline$>15$ years & 4 & 1.3 & 3 & 1.5 & & \\
\hline
\end{tabular}

Note. ${ }^{*}$ Based on Chi-Square; ${ }^{* *}$ Statistically significant

\subsection{Rating nurses' awareness of their influence on work in governmental and private hospitals}

Figure 2 demonstrates rating nurses' awareness of their influence on work among both study groups. The majority of both groups $(86.6 \%$ and $62.5 \%)$ reported the moderate perception level of their influence on work. But, regarding the high perception level of influence on work among both groups; it was in favor of the nurses who are working in the private hospital $(27.5 \%$ vs. $8 \%)$ and $p<.05$.

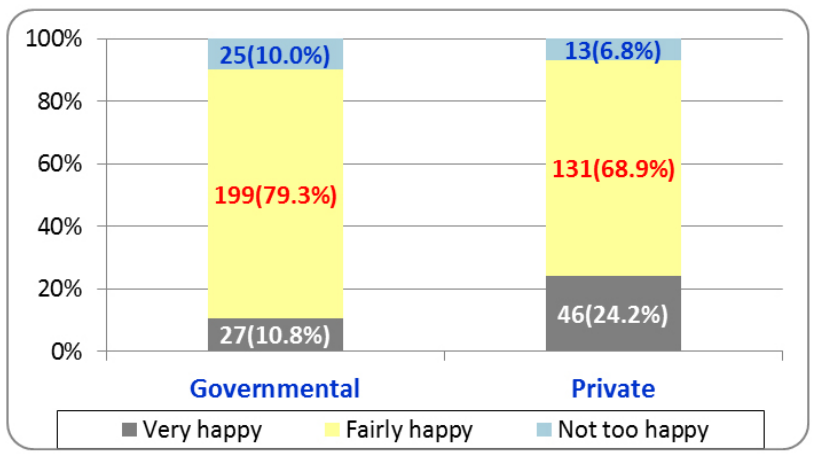

Figure 1. Rating of nurses' happiness according to the type of hospital as presented by percentages

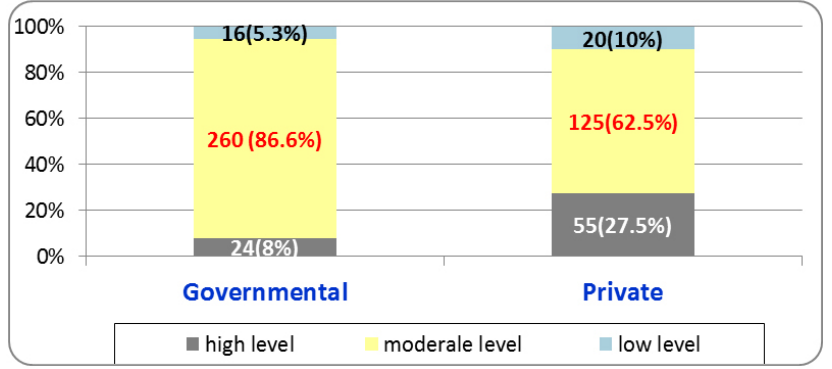

Figure 2. Rating of nurses' recognition of their influence on work among both study groups according to the type of hospital as presented by percentages

\subsection{Comparison between nurse's happiness and aware- ness of their influence on work in governmental and private hospitals}

Figure 3 illustrates a comparison between the levels of happiness and influence on work as perceived by study participants. (Low, moderate and high) which is the rating of the influence on work awareness, and in the same bar-chart, (not too happy, fair happy and very happy) is the rating for happiness at work. A positive correlation between nurse's perception of their influence on work and their happiness is observed because the chart clarifies that nurses who reported high scores in 
recognizing their influence on work are very happy and viceversa. Therefore, a stronger parallel correlation is noticed between the study variables and among both study groups.

Table 2 demonstrates the correlation and association between nurses' perception level of their influence on work and their rating of happiness at work. It is understandable that there is a stronger positive relationship between both variables and among nurses in governmental and private hospitals. Where Spearman's rho association test $r=0.752$ that is closing to 1 , for governmental hospital group, and $r=0.778$ for private hospital group which is undoubted, harmonious with the research hypothesis. The correlation coefficient among both research variables in both hospitals specified a remarkable stronger positive relation.

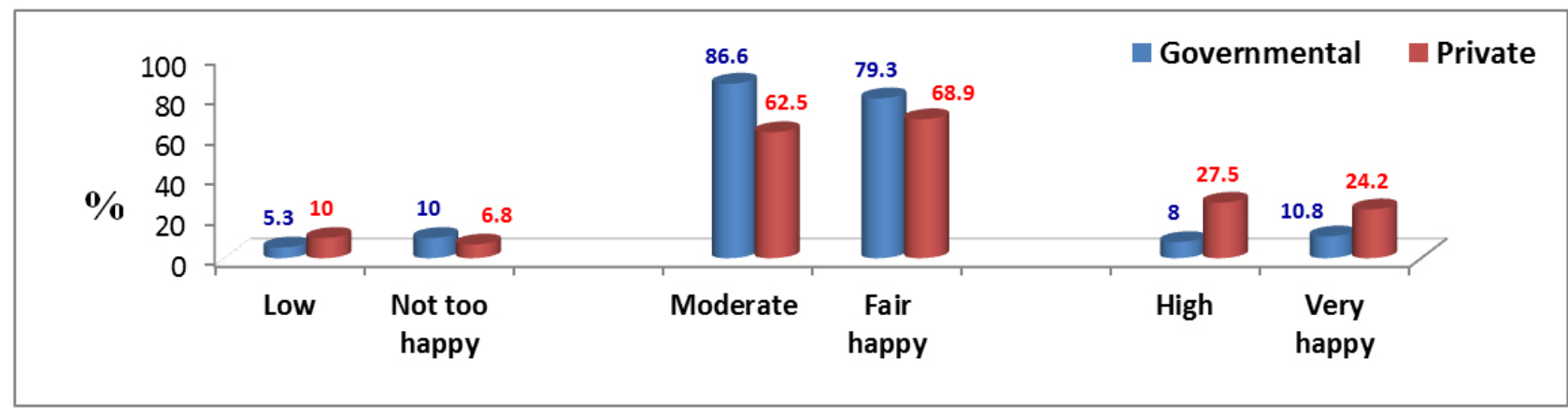

Figure 3. The correlation between nurses' influence on work and happiness according to the type of hospital as presented by percentages

\section{Discussion}

Nurses all over the world, have multiple physical and psychological needs. The nature of their job is forcing them to confront many risks and difficulties. Therefore, their emotional status should be investigated and handled carefully and regularly. In the same time, there is an urgent need to sustain and maintain nurses in their work positions, particularly among countries with a considerable shortage in the nursing workforce, such as KSA. Nurses' awareness of their influence on work and happiness in work are important concepts in nursing management. If both are high, nurses' job satisfaction and motivation will be maintained, and the nurse's performance will be better. ${ }^{[1,2,18]}$

Table 2. Correlation between nurses' influence on work and happiness according to the type of hospital and Pearson correlation

\begin{tabular}{|c|c|c|c|c|c|}
\hline & & \multicolumn{2}{|c|}{ Governmental } & \multicolumn{2}{|c|}{ Private } \\
\hline & & Influence on work & Happiness & Influence on work & Happiness \\
\hline \multirow{3}{*}{$\begin{array}{l}\text { Influence on } \\
\text { work }\end{array}$} & Pearson Correlation & 1 & $.752^{* *}$ & 1 & $.778^{* *}$ \\
\hline & Sig. (2-tailed) & & .005 & & .285 \\
\hline & $\mathrm{N}$ & 300 & 300 & 200 & 200 \\
\hline \multirow{3}{*}{ Happiness } & Pearson Correlation & $.752^{* *}$ & 1 & $.778^{* *}$ & 1 \\
\hline & Sig. (2-tailed) & .005 & & .285 & \\
\hline & $\mathrm{N}$ & 300 & 300 & 200 & 200 \\
\hline
\end{tabular}

Note. ${ }^{* *}$ Correlation Coefficient is significant at the 0.01 level (2-tailed); Spearman's rho used to quantify the strength of association between 2 numerical ordinal variables

According to the results of the current study, the personal profile among nurses in both hospitals declares that the majority of them are females and in their early twenties. This finding is observable worldwide due to the nursing job is femininity domination, and many studies demonstrate that the nature of the nursing work needs young employees. Similarly to this view, Bartfay et al., in 2010 and Price in 2011 documented that the nursing job had experienced greatly of the stereotyping and it is firmly bonded to youthful womanliness. This understanding among people is greatly biased and based on the interpretation of some aspects of culture and traditions. ${ }^{[19,20]}$ But, our community today, has an essential need to change this view, because we have a serious lacking in nursing staff. So, it is necessary to enhance the presence 
and participation of men in nursing work with a variety of age limit.

Approximately, all nurses in the present study, in both hospitals, are giving direct patients' care. In nursing work, assuming clinical work and direct patients' interventions is the most mental activity for exercises and catching nursing competency. Furthermore, in this work nature, nurses may confront several challenges and difficulties that enhance them to be more expertise. So, study subjects give a real and touchable report about themselves and their experiences. Corresponding with this view, Freitas et al., in 2014, explained that nurses who have direct contact with patients have basic responsibilities and duties that enable them to establish unique and real responses or feelings in their work. As well, they are, frequently with a substantial number and distributing in several nurse's departments. ${ }^{[21,22]}$ Thus, the current study gains real data, because almost of participants work directly with patients. Such data should be investigated carefully, to provide sound reflections on healthcare outcomes.

The majority of both study groups have a bachelor qualification. Many studies stressed that there are several hospitals, particularly in Arab countries, have an essential need for hiring qualified professionals with a bachelor degree in the nursing profession. Nurses with a bachelor qualification have the prerequisites to fit their job requirements and be competent in nursing work. Matching with this discussion, Abdel Kader et al., in 2012 reported that healthcare professionals should have proper educational preparations to confront and meet the requirements and challenges in their nursing work. ${ }^{[22,23]}$ For work experience years, the majority of both groups have five to ten years of experience in the hospital. Employees with longer duration of work experience have a secure emotional state and high self-value. Congruent with this finding, nurses with more work experience time, have an autonomous personality with high of and, self-direction, and self-actualization. Longer duration of work enables nurses to gain more competency and experience. Consequently, a nurse's psychological empowerment and work motivation will increase. On the contrary, beginner and new nurses show to be anxious and get a feeling of uncertainty and complaining from stress since they have a lacking of experience in nursing work performance. ${ }^{[2,10]}$

Globally, regarding the participant's profile, the results show that both study groups are similar in all sociodemographic characteristics, except in age variability and social status. The similarity and variations in a personal profile are expected since the majority of KSA nursing workforce is coming from different countries and races plus the Saudi nationality nurses. Therefore, social status and ages have to be

Published by Sciedu Press different among both groups. The current finding is in line with Al-Mutairi in 2015 in KSA who discussed that the kingdom has an extreme need for foreign workforce professionals in a nursing career with different qualifications, ages, and nationalities, to meet healthcare requirements. ${ }^{[12,23]}$ Accordingly it is a big challenge in KSA to maintain a sufficient number of the national workforce of nurses.

Concerning the first research question, the results in figure one and two illustrate adequate information to answer it. Almost all of both study groups have a fair level of happiness and a moderate level of awareness of their influence on work. Furthermore, nurses in the private sector are happier and have higher perception level of their influence on work than those in the governmental sector. Supporting this exciting result, Warr, in 2010 and 2013 explained that the happiness, satisfaction, and motivation in work are completing each other and are three indicators for work acceptance and work trustworthiness. Motivation is the cause that leads to satisfaction, and consequently, satisfaction leads to happiness. The three concepts are linked to the internal regulation category of work motivation that relies on the degree of employee recognition of one's influence on work. Internalized regulation is the most important type of motivational regulations that provide the real and valid driver for work achievement. ${ }^{[1,18,24]}$ Essentially, happiness and recognition of influence on work are major psychological needs for supporting nursing workforce. Additionally, Scott in 2008 reported that happiness at work is a basic aspect of nurses' work satisfaction. Happiness shaped the nurses' attitudes, identity, feelings, image, and self-concept positively in work. ${ }^{[1,25]}$ Furthermore, Toode et al., in 2014, Gagné et al., in 2010; and Ryan \& Deci, 2000, clarified that when the employees observe, recognize and report high perception level of their influence on work, this proved their internalized gratification, satisfaction, and pleasure regarding the work tasks and responsibilities. Thus, they tend to do their best at work throughout the motivation which was derived from their awareness about their level of influence on work. ${ }^{[5-7]}$

Corresponding to this insight, Basu in 2012 stressed that nurse's managers in private hospitals, frequently, tend to investigate hospital factors that can lead to nurse's happiness. Then, they have to enhance the positive factors to maintain nurses' happiness. But Alshmemri in 2014 conducted a study in the governmental hospital in KSA and reported that nurse's managers in governmental hospitals are not aware of the approaches to encourage happiness among nursing staff. ${ }^{[4,26]}$ Although nurse' workforce preservation, enthusiasm, and happiness are the major objectives among nurses' managers in governmental or private hospitals, it was observed that nurses in private hospital are happier than those 
who are working in governmental one. ${ }^{[23,26]}$ Keeping nursing staff happy is better than keeping work success. Because happiness among the workforce will lead to continuous staff commitment, then consistent success automatically will be reserved.

According to McGonagle in 2015, who described that there are many of psychological theories illustrated human behavior and provided a view of the demonstration of happiness analysis in nursing work. According to self-determination theory, the employee psychological need for competence, autonomy, and relatedness is a fundamental of experiencing happiness at the work environment. Subjective well-being and intrinsic appreciation of job tasks are the main results of employee happiness in work. ${ }^{[7,27]}$ Thus, workplace preparedness and organizational structure should be equipped with all features, facilities, policies, and rapport for enhancing employee happiness and internally recognition of one's influence on work.

According to the nature of community and country, particularly in KSA, there are some positive and negative factors in both health sectors (private and governmental) may lead to psychological disturbances among nurses. ${ }^{[4,12]}$ But, globally, the current study prove that the nurses' perception level of their influence on work and happiness in between both healthcare sectors, is accepted and comprehended. Nurses should receive suitable support to recognize their influence on work which continually empowers them to be happy and attain perfect performance.

With regard to the answer to the second research question, the rating of both study variables among both study groups proved that there is a strong parallel relationship between study variables. There are approximately equal highest percentages of both study groups, who have a moderate recognition level of their influence on work, and fairly happy. As well, nurses with a high recognition level of their influence on work, are very happy and vice versa. Certainly, this result is fitting the existing research hypothesis. The correlation coefficient among both study variables is remarkable with a strong positive association. This outcome was anticipated because nurses' happiness is a logical result of the high perception level of influence on work, and thus, the research variables are strongly paralleled. Pertaining, selfdetermination theory, the internally motivated employees, through the recognition of their influence on work, will be happy and have stable psychological well-being. Besides, and dependant on the role of nurse manager, the appreciation, recognition, and acknowledgment of employee work, will help to increase their awareness by their influence on work and consequently, happiness and competent performance will be obtained. ${ }^{[2,29,30]}$

Harmonious with this result, some pieces of evidence confirmed that internal motives, empowerment, and gratitude of self-value, are expected outcomes of one's awareness of own influence on work, and those outcomes are positively correlated with job happiness, job satisfaction, and job retention. Happiness and motivation are constructively controlled healthcare professionals' subjectivity and the perception of their influence on work. Moreover, nurses are the persons who are assuming a difficult work nature with patients and they need continuous motives and appreciation to be happy, thus, they can cope with work requirements. ${ }^{[2,5,11]}$ In the same line, Toode in 2015, Adjei et al., in 2016, and Mudallal et al., in 2017 mentioned that work happiness is positively correlated with a positive work climate, rewarding fairness system, work cooperation, engagement, and valuing of one's influence on work. However, happiness in the workplace has a negative association with absenteeism, stress, burnout, disappointment and psychological instability. ${ }^{[2,3,11]}$ Similarly, Warr, in 2013 clarified that the employees who are aware and recognize own competency and ability in the job, plus perceiving of the inner motive of own influence on work, would be most happy and productive. ${ }^{[1,5]}$

Mismatching, with this result, Warr in 2006 and 2010 stressed that the failed employees who have a high level of awareness about their performance in work, have inadequate competencies and unacceptable performance and tend to be frustrated. So, recognition of personal influence on work should be used only with the competent and achiever employees. ${ }^{[8,18]}$

Almalki, in 2012, Alshmemriin 2014 and Al-Mutairi in 2015 in KSA, reported that the kingdom complained of a serious lacking in the nursing workforce, all over kingdom regions. ${ }^{[4,12,23]}$ Therefore, to manage this problem and reserve nurses in their jobs, the current study will be a guide to determine the several factors affecting the nurses' psychological condition. The parallel correlation between nurses' happiness and awareness of their influence on work in private and governmental sectors, in Jeddah, will provide a key data to prepare a fitting plan for encouraging and maintaining nurses' happiness and awareness of one's influence on work among Saudi nurses. Also, it helps the Nurse Manager to determine the emotional needs of nurses and fulfill deficiencies or promote positive attitudes. The recent study is exceptional research that investigates such variables.

\section{CONCLUSION AND RECOMMENDATIONS}

Saudi nurses in Jeddah, in private and governmental hospital, having a moderate awareness level of their influence on work 
with a fair level of happiness in the workplace. Nurses, who are working in a private hospital, are happier and have a high recognition level of their influence on work than those who are working in the governmental hospital. There is a strong parallel association between nurses' happiness and awareness of influence on work among Saudi nurses in governmental and private hospitals, in Jeddah. Therefore, Saudi nurses have to determine the benefits to be aware of the factors that enhance their happiness and their awareness about work performance. Nurses' Managers are obliged to prepare a fitting plan for enhancing the factors that are affecting nurses' psychological condition stability. The governmental hospitals in Jeddah have to investigate why the nurses in the private sector are happier than those in governmental one. The private or governmental hospitals should implement all measures to improve nurses' perception regarding their influence on work and their happiness. More to the point, both study variables and its correlation are necessary to be investigated and encouraged by nurse managers and nurse administrations. Furthermore, both study variables and the variation in governmental or private healthcare systems should be integrated into the nursing curriculum. Further researches are required to determine the impact of a training program about handling nurses' emotional status in work on nurse manager's managerial skills. A study about nurses' happiness in the workplace and other increasing or decreasing factors in governmental and private sectors is needed.

\section{ACKNOWLEDGeMENTS}

The authors are thankful to the Deanship of Scientific Research through the Research Center at the College of Nursing, King Saud University, KSA for support of current research.

\section{CONFlicts OF INTEREST Disclosure}

The authors declare they have no conflicts of interest.

\section{REFERENCES}

[1] Warr P. Jobs, and job-holders: two sources of happiness and unhappiness. In The Oxford Handbook of Happiness (David, S.A., Boniwell, I. \& Ayers, A.C., eds). Oxford, UK: Oxford University Press; 2013. 733-750 p. https://doi.org/10.1093/oxfordhb/978019955 7257.013 .0054

[2] Toode K, Routasalo P, Helminen M, et al. Hospital nurses' working conditions in relation to motivation and patient safety. Nursing Management. 2015; 21(10): 31-41. PMid: 25727441. https : //doi.org/10.7748/nm.21.10.31.e1293

[3] Mudallal RH, Saleh M, Al-Modallal HM, et al. Quality of nursing care: The influence of work conditions, nurse characteristics and burnout. International Journal of Africa Nursing Sciences. 2017; 7(4): 24-30. https://doi.org/10.1016/j.ijans.2017.06.002

[4] Alshmemri M. Job satisfaction of Saudi nurses working in Saudi Arabian governmental hospitals. School of health sciences, discipline of nursing and midwifery. Royal Melbourne Institute of Technology, published Phd thesis. Jordan University. 2014; 1-33.

[5] Toode K, Routasalo P, Helminen M, et al. Hospital nurses' individual priorities, internal psychological states and work motivation. International Nursing Review, International Council of Nurses. 2014; 61(3): 361-370. PMid: 25091088. https://doi.org/10.1111/inr.12 122

[6] Gagné M, Forest J, Gilbert MH, et al. The Motivation at Work Scale: Validation evidence in two languages. Educational and Psychological Measurement. 2010; 70: 628-646. https://doi.org/10.1177/ 0013164409355698

[7] Ryan RM, Deci EL. Intrinsic and extrinsic motivations: classic definitions and new directions. Contemporary Educational Psychology. 2000; 25: 54-67. PMid: 10620381. https://doi.org/10.1006/ ceps. 1999.1020

[8] Warr PB. Differential activation of judgments in employee well-being. Journal of Occupational and Organizational Psychology. 2006; 79: 225-244. https://doi.org/10.1348/096317905X52652

[9] Thirapatsakun T, Kuntonbutr C, Mechinda P. The Relationships among Job Demands, Work Engagement, and Turnover Intentions in the Multiple Groups of Different Levels of Perceived Organizational Supports. Universal Journal of Management. 2014; 2(7): 272-285.

[10] Lambrou P, Kontodimopoulos N, Niakas D. Motivation and job satisfaction among medical and nursing staff in a Cyprus governmental general hospital. Human Resources for Health. 2010; 8: 26. PMid: 21080954. https://doi.org/10.1186/1478-4491-8-26

[11] Adjei KA, Emmanuel O, Forster OM. The Impact of Motivation on the Work Performance of Health Workers (Korle Bu Teaching Hospital): Evidence from Ghana. Hospital Practices and Research. 2016; 1(2): 47-52. https://doi.org/10.20286/hpr-010245

[12] Almalki MJ, Gerald GF, Clark M. Quality of work life among primary health care nurses in the Jazan region, Saudi Arabia: a cross-sectional study. Bio Med Central, Hum Resour Health. 2012; 10: 30. PMid: 22971150. https://doi .org/10.1186/1478-4491-10-30

[13] Peters D, Chakraborty S, Mahapatra B, et al. Job satisfaction and motivation of health workers in governmental and private sectors: cross-sectional analysis from two Indian states. Human Resources for Health. 2010; 8: 27. PMid: 21108833. https://doi .org/10 $.1186 / 1478-4491-8-27$

[14] Miller CA. Nursing for Wellness in Older Adults: Theory and Practice (4th eds.). Philadelphia, PA: Lippincott Williams \& Wilkins; 2004.

[15] Jun WH, Jo MG. Factor affecting happiness among nursing students in South Korea. Journal of Psychiatric and Mental Health Nursing. 2016; 23: 419-426. PMid: 27500983. https ://doi.org/10.111 $1 / j p m .12330$

[16] Rosner B. Fundamentals of Biostatistics: Solutions Manual. 5th ed 1999.

[17] Warr P, Cook J, Wall T. Scales for the measurement of some work attitudes and aspects of psychological well-being. Journal of Occupational Psychology. 1979; 129-148. https://doi.org/10.1111/ j. 2044-8325.1979.tb00448.x

[18] Warr PB, Clapperton G. The joy of work? Jobs, happiness, and you New York: Routledge; 2010. 
[19] Bartfay WJ, Bartfay E, Clow KA. Attitude and perceptions towards men in nursing. Journal of Allied Health Sciences and Practice. 2010; 8(2): $2-7$.

[20] Price SL. The Experience of Choosing Nursing as a Career: Narratives from Millennial Nurses. Published PHD Theses, Lawrence S. Bloomberg Faculty of Nursing: University of Toronto; 2011. 1- 46, 55-180 p.

[21] Freitas AR, Carneseca EC, Paiva CE, et al. Impact of a physical activity program on the anxiety, depression, occupational stress and burnout syndrome of nursing professionals. Rev. Latino-Am. Enfermagem. 2014; 22(2): 332-6. PMid: 26107843. https : //doi .org/ 10.1590/0104-1169.3307.2420

[22] Abdel Kader AM, Mohamed EA, Abood SA. Perception of Nurse Interns about Clinical Assignment Preparation Requirements. Journal of American Science. 2012; 8(12): 676-682.

[23] Al-Mutairi E. Healthcare Workforce Challenges in Saudi Arabia (A Brief Overview). 2015. Available from: www.csc.org.sa/ . . /Healthcare $\% 2$ Workforce $\% 20$ Gap $\% 20$ in $\% 20$ Saudi $\% 20$ Arabia.pdf

[24] Hontake T, Ariyoshi H. Astudy on work engagement among nurses in Japan: the relationship to job-demands, job-resources, and nursingcompetence. Journal of Nursing Education and Practice. 2016; 6(5). https://doi.org/10.5430/jnep.v6n5p111
[25] Scott DE. Happiness at Work. Center for American Nurses. 2008; $1-5$.

[26] Basu S, Andrews J, Kishore S, et al. Comparative Performance of Private and Governmental Healthcare Systems in Low- and MiddleIncome Countries: A Systematic Review. PLoS Med. 2012; 9(6): e1001244. PMid: 22723748. https://doi.org/10.1371/jour nal.pmed. 1001244

[27] McGonagle C. Happiness in the workplace: an appreciative inquiry. A thesis presented to Dublin City University in partial fulfilment of the requirements for the degree of Doctor of Education. School of Education Studies. 2015; 23-76.

[28] Dar S, Zehra N, Ahmad F. Extrinsic Factors Strong Motivators for Nurses in the Tertiary Care Hospitals. Pakistan Journal of Medicine and Dentistry. 2014; 3(1); 31-36.

[29] Awosusi O, Jegede AO. Motivation and job performances among nurses in the Ekiti State environment of Nigeria. International Journal of Pharma and Bio Sciences. 2011; 22(2): 583-595.

[30] Willis-Shattuck M, Bidwell P, Thomas S, et al. Motivation and retention of health workers in Arabian countries: a systematic review. BMC Health Serv Res. 2008; 4(8): 247. PMid: 19055827. https ://doi .org/10.1186/1472-6963-8-247 